\title{
1 NESTE NOSSO TEMPO ATÍPICO
}

| Lucília Nunes ${ }^{1} \mid$

Uma das referências que tem aparecido com frequência é que vivemos um tempo atípico, que 2020 é um ano atípico. Tomamos por «atípico» o que se afasta do normal ou do esperado, o que é anómalo, o que se nos apresenta como anormal, irregular, fora da regra ou do habitual. Provavelmente, é uma expressão suficientemente clara e, ao mesmo tempo, equívoca, para caracterizar este nosso tempo.

O surgimento e a rápida disseminação do novo coronavírus colocaram desafios inesperados a todas as entidades e em todos setores - nenhum país, sistema de saúde ou instituição estava preparado para uma pandemia com a dimensão e as repercussões que vivemos. A pandemia constitui, por um período que se estima poder ser longo, um teste difícil para todos. Em bom rigor, não conhecemos uma ameaça infeciosa desta magnitude desde a pandemia de influenza de 1918. Em poucos meses, entrámos em modo de emergência, os serviços de saúde focados no combate à infeção por SARS-COV-2, as famílias voluntária ou compulsivamente confinadas e a economia quase paralisada.

Tempo atípico significa que vivemos um tempo marcado pela situação pandémica, que é complexa e evolutiva, suscita incerteza e instabilidade, requer de nós, seres sociais, que mantenhamos distanciamento social. Como se afirma no parecer do CNECV "A necessidade de tomar decisões, numa escalada necessariamente modelada pelo próprio desenvolvimento da situação pandémica, confronta-se com princípios, valores e direitos das pessoas e da sociedade em geral." (Comissão Nacional de Ética para as Ciências da Vida, 2020). Desde logo, emergiram questões éticas, de proteção da vida e da dignidade humana, relacionadas com os princípios da necessidade, da precaução, da proporcionalidade, da solidariedade.

Também se foi tornando claro que algumas consequências deste ano atípico poderão alastrar aos próximos anos - e pensemos concretamente na Saúde Mental.
A vivência da pandemia não trouxe apenas o confinamento ou o distanciamento físico. Alguns medos agigantaram-se; o medo da doença, o aumento do stress e da ansiedade, a incerteza do futuro. $\mathrm{O}$ que tem sido designado por impacto psicológico da pandemia, mas também as consequências concretas relacionadas com o aumento do desemprego, a crise económica, e uma conjugação complexa de fatores que potencia angústia existencial.

Vejamos algumas coisas que sabemos, das evidências existentes. Sabemos que o isolamento e a quarentena podem desencadear um conjunto de sintomas psicopatológicos, designadamente perturbações depressivas e perturbações de stress pós-traumático.

Sabemos que a pandemia aumenta a vulnerabilidade, quer do ponto de vista emocional quer pelas dificuldades económicas - existe uma forte relação entre saúde mental e privação social e evidências que o aumento do desemprego se relaciona com agravamento da saúde mental.

Sabemos que as pessoas morrem neste tempo de pandemia e os seus familiares e amigos vivem a privação da despedida, o sofrimento da perda em isolamento no período de luto, o que pode vir a ter repercussões sérias na saúde mental.

Também sabemos que a saúde dos enfermeiros está a ser afetada pela sobrecarga, a exaustão e as exigências do contexto pandémico, acrescidas do risco e do receio de adoecer e de infetar amigos e família, receios que se traduzem em maiores níveis de ansiedade, stress e sintomas depressivos (Sampaio, Sequeira, \& Teixeira, 2020). Sabemos que os problemas de saúde mental têm consequências severas na vida das pessoas e dos que as rodeiam, incluindo familiares e outros cuidadores.

Não conseguimos, naturalmente, ajuizar sobre os impactos de médio e longo prazo destes tempos atípicos. Todavia, como Enfermeiros de Saúde Mental, temos recursos e meios para ajudar, para intervir.

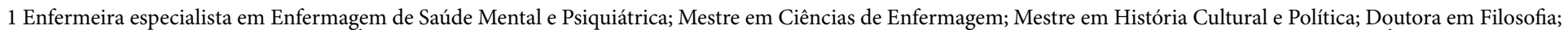

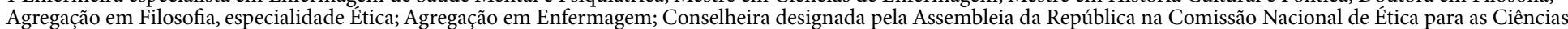

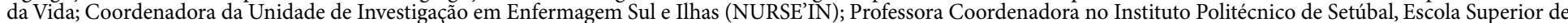
Saúde, Campus do Instituto Politécnico de Setúbal, Estefanilha, 2914-503 Setúbal, Portugal, lucilia.nunes@ess.ips.pt 
"O enfermeiro especialista em saúde mental compreende os processos de sofrimento, alteração e perturbação mental do cliente assim como as implicações para o seu projeto de vida, o potencial de recuperação e a forma como a saúde mental é afetada pelos fatores contextuais." (Regulamento n. ${ }^{\text {515/2018). }}$

A especificidade da prática clínica em Enfermagem de Saúde Mental permite estabelecer relações de confiança e parceria com a pessoa, aumentar o insight sobre os problemas e a capacidade de encontrar novas vias de resolução. Não teria dúvidas em afirmar que a primeira responsabilidade do enfermeiro especialista em Saúde Mental é respeitar a dignidade da pessoa (Franco, Caldeira, \& Nunes, 2020) e proteger os seus direitos, zelando pela qualidade e a segurança dos cuidados.

Claro que acabámos de passar para o território da ética profissional, que regula a relação do enfermeiro com aqueles a quem presta cuidados, tendo em conta a dignidade humana, os direitos das pessoas e as competências necessárias para o exercício. Em situação de necessidade, as pessoas podem ter diminuída a sua liberdade e nem ter consciência (ou capacidade) de pedir ajuda. Evitando psiquiatrizar a atual vida social, ainda assim importa reconhecer a especial delicadeza deste nosso tempo atípico, em que cruzam e entretecem a Ética e a Enfermagem de Saúde Mental. Diria mais: é tempo de visibilizar e valorizar os contributos da Enfermagem de Saúde Mental na promoção, a prevenção, a intervenção, tratamento, reabilitação e reinserção psicossocial.
Este nosso tempo atípico é também tempo de focar na dignidade humana, na compaixão e solidariedade, na justiça e equidade. Que o sentido de estarmos sitiados não nos imobilize - que, antes, nos sirva de impulso para a resiliência e a intervenção profissional.

\section{REFERÊNCIAS BIBLIOGRÁFICAS}

Conselho Nacional de Ética para as Ciências da Vida. (2020). Posição sobre a "situação de emergência de saúde pública pela pandemia covid-19: Aspetos éticos relevantes". Disponível em https://www.cnecv.pt/pt/comunicacoes/tomada-de-posicao

Franco, H., Caldeira, S., \& Nunes, L. (2020). Dignity in nursing: A synthesis review of concept analysis studies. Nursing Ethics. doi:10.1177/0969733020961822

Regulamento n. ${ }^{\circ}$ 515/2018 (2018). Regulamento de competências específicas do enfermeiro especialista em enfermagem de saúde mental e psiquiátrica. Disponível em https://dre.pt/application/conteudo/115932570

Sampaio, F., Sequeira, C., \& Teixeira, L. (2020). Nurses' mental health during the covid-19 outbreak: A crosssectional study. Journal of Occupational and Environmental Medicine, 62(10), 783-787. doi:10.1097/ JOM.0000000000001987 